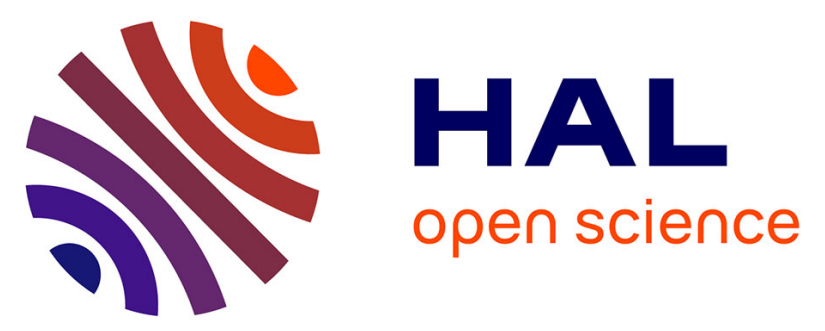

\title{
Multi-physics modeling and Au-Ni/Rh coating assessment for ITER ion cyclotron resonance heating radio-frequency sliding contacts
}

Z. Chen, Julien Hillairet, Viviane Turq, Y. Song, Raphäl Laloo, K. Vulliez, J.M. Bernard, Q. Yang, G. Lombard, C. Hernandez, et al.

\section{To cite this version:}

Z. Chen, Julien Hillairet, Viviane Turq, Y. Song, Raphaël Laloo, et al.. Multi-physics modeling and $\mathrm{Au}-\mathrm{Ni} / \mathrm{Rh}$ coating assessment for ITER ion cyclotron resonance heating radio-frequency sliding contacts. 2017 IEEE Holm Conference on Electrical Contacts, Sep 2017, Denver, United States. 10.1109/HOLM.2017.8088059 . cea-01851802

\section{HAL Id: cea-01851802 https://hal-cea.archives-ouvertes.fr/cea-01851802}

Submitted on 30 Jul 2018

HAL is a multi-disciplinary open access archive for the deposit and dissemination of scientific research documents, whether they are published or not. The documents may come from teaching and research institutions in France or abroad, or from public or private research centers.
L'archive ouverte pluridisciplinaire HAL, est destinée au dépôt et à la diffusion de documents scientifiques de niveau recherche, publiés ou non, émanant des établissements d'enseignement et de recherche français ou étrangers, des laboratoires publics ou privés. 


\title{
Multi-physics Modeling and Au-Ni/Rh Coating Assessment for ITER Ion Cyclotron Resonance Heating Radio-Frequency Sliding Contacts
}

\author{
Z. Chen ${ }^{1 *}$, J. Hillairet ${ }^{1}$, V. Turq ${ }^{2}$, Y. Song ${ }_{5}^{3}$, R. Laloo ${ }^{2}$, K. Vulliez ${ }^{4}$, J.M. Bernard ${ }^{1}$, Q. Yang ${ }^{3}$, G. Lombard ${ }^{1}$, C. Hernandez ${ }^{1}$, L. \\ Ferreira $^{5}$, F. Fesquet ${ }^{5}$, P. Mollard ${ }^{1}$, R. Volpe $^{1}$, F. Ferlay $^{1}$ \\ ${ }^{1}$ CEA, IRFM, F-13108 Saint-Paul-Lez-Durance, France \\ ${ }^{2}$ Institut Carnot CIRIMAT, UMR CNRS-UPS-INP 5085, Université Paul-Sabatier, 118 route de Narbonne, 31062 Toulouse \\ cedex 9, France \\ ${ }^{3}$ Institute of Plasma Physics, CAS, Hefei, Anhui 230031, China \\ ${ }^{4}$ Laboratoire d'étanchéité, DEN/DTEC/SDTC, CEA, 2 rue James Watt 26700 Pierrelatte, France \\ ${ }^{5}$ CERN, Geneva, Switzerland
}

\begin{abstract}
ITER is a large scale fusion experimental device under construction in Cadarache (France) intended to prove the viability of fusion as an energy source. Ion Cyclotron Resonance Heating (ICRH) system is one of the three heating systems which will supply total heating power of $20 \mathrm{MW}(40-55 \mathrm{MHz})$ up to one hour of operation. Radio-Frequency (RF) contacts are integrated within the antennas for assembly and operation considerations, which will face extremely harsh service conditions, including neutron irradiation, heavy electrical loads (RF current reaches up to $2 \mathrm{kA}$ with a linear current density of $4.8 \mathrm{kA} / \mathrm{m}$ ) and high thermal loads. Based on the thermal analysis, the contact resistance is expected to be lower than $7 \mathrm{~m} \Omega$ to keep the maximum temperature on the louvers lower than $250^{\circ} \mathrm{C}$. Few weeks of vacuum $\left(\sim 10^{-5} \mathrm{~Pa}\right)$ baking at $250^{\circ} \mathrm{C}$ for outgassing is expected before each plasma experimental campaign, under which the RF contact materials' mechanical properties change and diffusion phenomena between different materials are inevitable. CuCrZr and 316 $\mathrm{L}$ are proper base materials for ITER RF contact louvers and conductors respectively. In order to improve the RF contact's wear and corrosion resistivity as well as to reduce the contact resistance, $\mathrm{Au}-\mathrm{Ni}$ and $\mathrm{Rh}$ functional layers could be electroplated on $\mathrm{CuCrZr}$ and 316L accordingly. The application of the Au-Ni/Rh coating pairs is assessed through the thermal ageing and diffusion tests. Wear and electrical contact performances of the $\mathrm{Au}-\mathrm{Ni} / \mathrm{Rh}$ pairs are deeply studied on a dedicated tribometer operated at ITER relevant conditions.
\end{abstract}

Keywords- ITER, sliding RF contact, modeling, thermal ageing effect, tribology

\section{INTRODUCTION}

Compared with nuclear fission, nuclear fusion offers a safe, long term source of energy with abundant resources and major environmental advantages. In order to study the physics and technological issues for the development of fusion reactors, the world largest tokamak-ITER is currently under construction in Cadarache, France[1]. The investigation and demonstration of burning plasmas especially steady-state plasmas is one of the most important objectives for ITER [2], and $400 \mathrm{MW}$ of fusion energy for long durations (300-500 s) is aimed to be achieved. External heating systems are necessary to heat up plasma to a point where the fusion reactions initiated, and for ITER 73MW of external heating power will be achieved[1]. The Ion
Cyclotron Resonance Heating (ICRH) system is a major part of the heating and current drive system for ITER which will be used to provide $20 \mathrm{MW}(40-55 \mathrm{MHz}) \mathrm{RF}$ power for plasma heating during D-T operation, using the second-harmonic tritium resonance near the center of the plasma to heat the ions [3]. As Fig. 1 shows, each of the ITER ICRH antennas was designed as port plug (PP) structure with total weight of 45 tons[4]. The antenna can be described by three kinds of components: the front module (FM) which faces plasma directly, the transmission lines (TL) which are connected the RF sources and eight removable vacuum transmission lines (RVTL) [5]. For plasma coupling consideration, the FM must be capable of radial displacement for few centimeters relative to the RVTL to realize the shimming of the FM as well as to compensate the thermal expansion of the components so as to decrease the thermal stresses $[4,6]$. In addition, as a nuclear related facility, the ITER ICRH antenna components are expected to be assembled and maintained by using remote handlings, which requires flexible connections between each components. Based on the above design requirements, at least three flexible RF contact plugs were designed and installed on each RVTL.

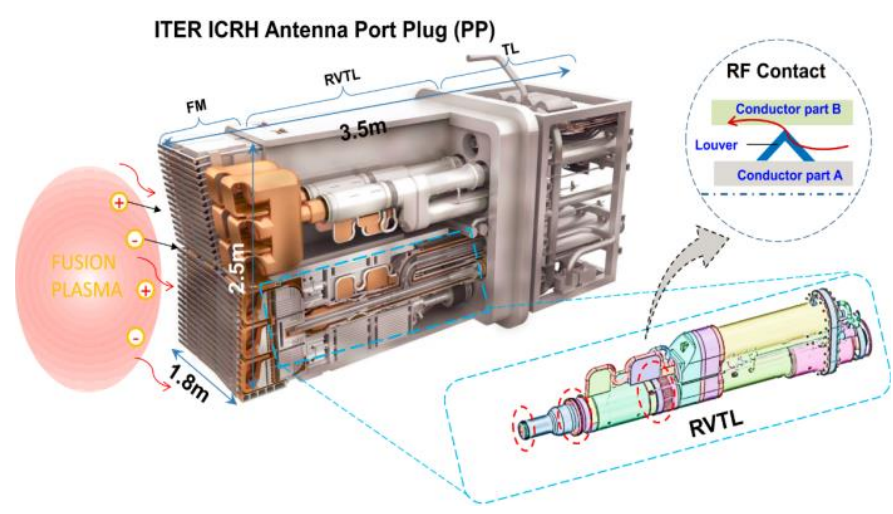

Fig. 1 Overview of the ITER ICRH antenna port plug design

The ITER ICRH RF contacts will be working under heavy load of RF current which can reach up to $2 \mathrm{kA}$ representing a current density of $4.8 \mathrm{kA} / \mathrm{m}$. Such a heavy current load will induce large thermal load especially at the contact area, where 
the contact resistance is generated. In practice, applying functional coatings on the surface of RF contact surfaces is a useful technique to minimize the contact resistance. However, as the ITER RF contact will be working under high temperature and high vacuum conditions [6, 7], repetitive sliding between the RF contact louvers and its counterpart shortens the lifetime of the function coatings. In CEA, RF tests under ITER relevant conditions were performed on two ITER ICRH RF sliding contact prototypes, and melting or burn occurred as a result of high thermal load deposition. An electrical-thermal analysis model of the ITER ICRH RF sliding contact was created taking into account the active water cooling, structural materials and contact resistances to the temperature distribution on the RF contact louvers. Aiming to improve the contact resistance as well as to enhance the wear resistivity, Au-Ni and Rh coatings will be applied on the ITER RF sliding contact louvers and conductors respectively. The materials diffusion phenomenon under ITER high temperature baking conditions and the electrical/tribological performance of this coating pairs has been assessed and is detail introduced in the next section.

\section{FAILURE MECHANISM INVESTIGATION AND ELECTRICAL- THERMAL ANALYSES}

Due to the large uncertainties on contact resistance and heat transfer coefficient of the RF sliding contact, its performance forecast under the above working conditions is difficult [8]. Therefore, qualification tests in relevant conditions and representative geometry are necessary to validate these critical components. In order to test and validate the anticipated RF contacts in operational conditions, CEA has prepared a dedicated test bed consisting of a steady-state vacuum pumped $\mathrm{RF}$ resonator which has been installed within the TITAN (Testbed for ITer icrh ANtenna) facility. This setup is capable of testing the RF sliding contact prototypes under vacuum $\left(<10^{-4} \mathrm{~Pa}\right)$ with $\mathrm{RF}$ current up to $2.25 \mathrm{kA}$ at $62 \mathrm{MHz}$ and during $20^{\prime}-30^{\prime}$ using an hot pressurized water loop $\left(250^{\circ} \mathrm{C} / 44 \mathrm{bar}\right)$ [9$11]$.

\section{A. RF test results of the prototypes}

Two types of ITER ICRH RF sliding contacts (with outer diameter of $130 \mathrm{~mm}$ ) were tested on TITAN. Titanium is the currently selected as the structure material for the ITER ICRH antenna RVTL. As Fig.2(a) shows, a real scale sliding RF contacts was manufactured under the collaboration with CYCLE (CYclotron Cluster for Europe) by CCFE (Culham Centre for Fusion Energy), on which a copper strap with louvers was brazed. A layer of pure copper was plated on the component to minimize the RF losses and then a thin layer of gold-nickel was applied on the whole surface for lubrication and oxidation prevention [10]. In order to realize the good contact between the louvers to the opposite conductor, a coil spring made of stainless steel was installed under the louvers. During this test, a $1700 \mathrm{~A} / 1200 \mathrm{~s}$ and $2480 \mathrm{~A} / 50 \mathrm{~ms}$ operations were achieved. After that, the RF current couldn't be injected into TITAN anymore, and when disassembled serious melting on the coil spring and burn traces on the louvers were observed [9].
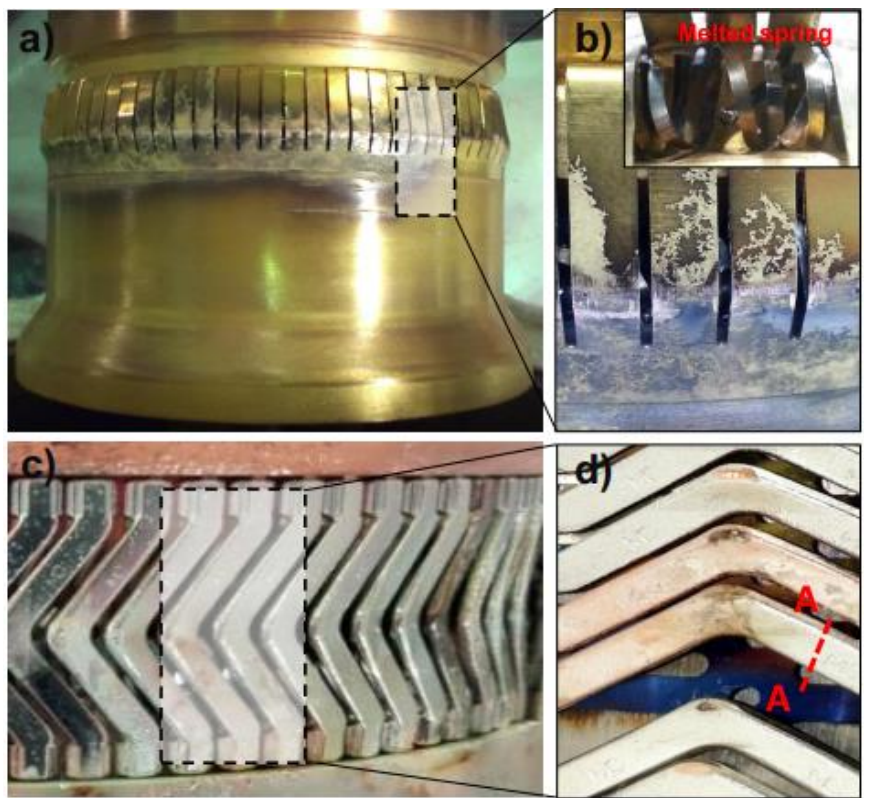

Fig.2. Results of the RF tests performed on the two prototypes: (a). CCFE RF contact prototype after RF tests; (b). Detail view of the burned louvers and melted coil spring; (c). LA-CUT ${ }^{\circledR}$ RF contact after RF tests; (d). Detail view of the burned louvers.
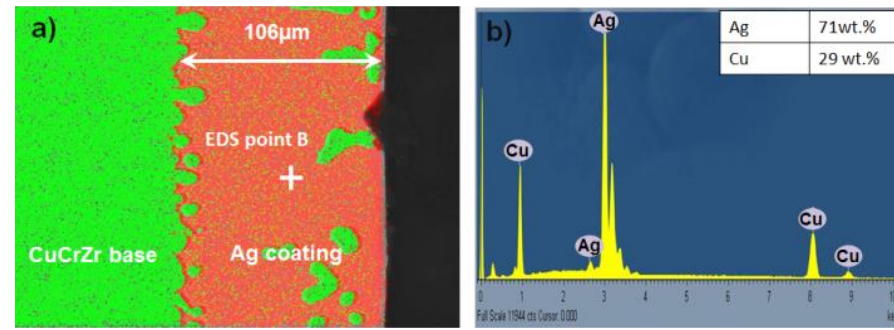

Fig. 3 EDS results of LA-CUT ${ }^{\circledR}$ tested louver: (a). EDS mapping of the cross section along A-A (Fig.2); (b). EDS analysis at point B.

Recently, a new campaign of RF test was carried out based on the commercial LA-CUT® contact by cooperating with Multi-Contact $\AA$. The new tested RF contact prototype is composed by a set of triangle contact louvers and a thin stainless steel plate that supplies the normal contact force between the RF contact louvers to the opposite conductor. $\mathrm{CuCrZr}$ has excellent thermal and electrical conductivities as well as acceptable mechanical properties under high temperature and had already been selected as base material to manufacture many ITER key components that aimed for high heat fluxes handling [12-16]. CuCrZr alloy has been selected instead of pure $\mathrm{Cu}$ for $\mathrm{RF}$ contact louvers manufacturing in order to sustain $250^{\circ} \mathrm{C}$ long time baking without serious creeping. On the $\mathrm{CuCrZr}$ contact louvers, a $32 \mu \mathrm{m}$ thick Ag coating had been applied to improve the contact's electrical performance. During this operation, 1200s RF operation under $1.5 \mathrm{kA}$ and $300 \mathrm{~s}$ RF operation under $1.9 \mathrm{kA}$ were achieved. After the 1.9kA test, the RF power couldn't be injected into the RF resonator anymore. After disassembly, serious burn traces was observed on the RF contact prototype (Fig.2 (d)) and some of them were melted. As shown in Fig.3(a) and Fig.3 (b), by cutting the burned louver and analyzed by using EDS, the diffusion phenomenon of copper into the Ag coating layer was observed. Because of high RF power deposition, the temperature on the RF contact louvers increased and the diffusion of $\mathrm{Cu}$ atoms into $\mathrm{Ag}$ layer was accelerated, as a result the thickness of Ag layer increased from its initial value to 
more than $106 \mu \mathrm{m}$. In the Ag layer, there were copper phase precipitated which is due to the solid solubility decrease of the $\mathrm{Cu}$ into the $\mathrm{Ag}$ base. The material change in the Ag coating can impair its corrosion resistance, mechanical and electrical properties. Besides, on the tips of the RF contact louvers, the initial Ag coating was worn out.

Based on the RF tests, it showed that the self-heating and high temperature diffusion phenomena of the RF contact under ITER relevant operation condition should be carefully studied during the ITER ICRH RF contact development. Coatings with better wear performance are expected to be developed.

\section{B. Modeling and analysis}

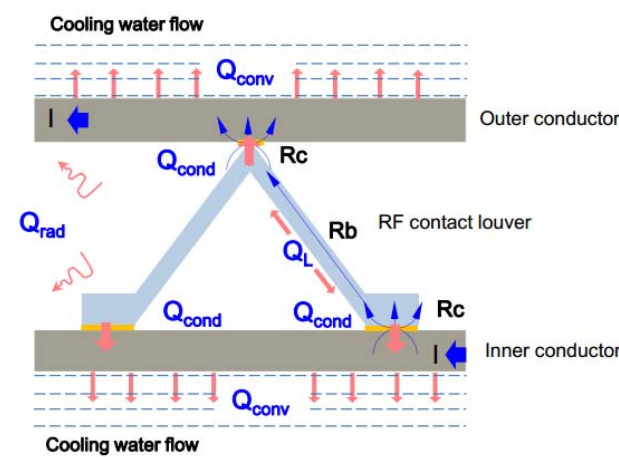

a)

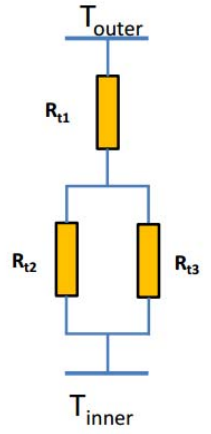

b)
Fig. 4 Sketch of the ITER RF contact analysis model: (a). thermal-hydraulic model. (b). thermal contact resistance of RF contact louver

In order to model the heating phenomenon and temperate response of the RF contact louver during operation, an analysis model was created as shown in Fig.4. During operation, there are two heat generation sources: RF losses due to the bulk resistance $\left(R_{b}\right)$ and RF loss due to contact resistances $\left(R_{c}\right)$. Under the contact force, the RF contact louvers are closely contacted with the holder and the opposite conductors, so thermal conductance is the driving heat transfer phenomenon for heat removal since the setup is under vacuum. In order to insure steady-state operation, an active cooling with inlet temperature of $90^{\circ} \mathrm{C}$ was used, which corresponds to the highest water temperature in ITER during RF operation.

\section{1) Analysis model and boundary conditions}

An electrical-thermal multi-physics model was created in ANSYS as shown in Fig.5, four RF contact louvers and pieces of conductors were considered. For cooling point of view, the thicknesses of the conductor should be as thin as possible. However, the cooling channel on the conductors must have enough mechanical strength to sustain the ITER ICRH cooling water pressure which reaches up to 60 bars. In the analysis model both the thicknesses of the inner and outer conductor cooling channel covers were determined to be $3.5 \mathrm{~mm}$. In this model, the current densities in each of the RF contact louvers were assumed as uniform, and a total current of 78.4 A DC was applied on the model with an average of $19.6 \mathrm{~A} /$ louver. The latter value is comparable to the current density of ITER design specifications. At the top and base contact areas, thermal contact conductance and electrical contact conductance were applied. For the thermal conductance, the values were obtained from a measurement on a special designed test bed in CEA. The thermal contact conductance on the tip contact and base contact areas are $4075 \mathrm{~W} / \mathrm{m}^{2} \cdot \mathfrak{C}$ and $10570 \mathrm{~W} / \mathrm{m}^{2} \cdot \mathfrak{C}$ respectively. The electrical contact conductance is one of the parameters that are expected to be studied from the analysis, which can indicate the effects of contact resistance to the temperature on the RF contact. Heat transfer coefficients (HTC) and water temperature were applied on the surfaces of the inner and outer conductors directly to simulate the cooling water effects, and its efficiency for heat removal was analyzed. At last, the relation between the base material choices of the conductors to the operation temperature on the RF contact was researched.

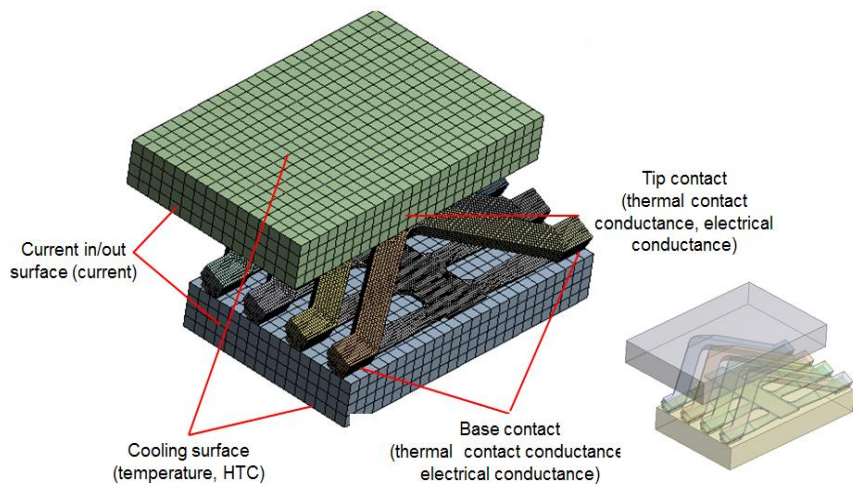

Fig. 5 Analysis model and boundary conditions

\section{2) Results of current density and RF losses}

In this analysis, the base materials of the inner and outer conductors were set to stainless steel $316 \mathrm{~L}$. The material of the $\mathrm{RF}$ contact louvers is $\mathrm{CuCrZr}$. The distributions of current density and Joule heat due to Ohmic losses are shown in Fig.6. On the RF contact louvers, the current density in the side near to the current inlet is about six times higher than the side far from the current inlet. It can also be observed that, the maximum Joule heat generated at the contact area which is caused by the contact resistance $\mathrm{R}_{\mathrm{c}}$. In addition, the heat losses on the surface of the stainless-steel conductor are higher than that on the RF contact louvers. Active cooling to remove heat deposition on the conductors is very necessary not only for the RF contact louvers but also for the RF conductors. The analyses under the $R_{c}=1 \mathrm{~m} \Omega, 2 \mathrm{~m} \Omega, 4 \mathrm{~m} \Omega, 7 \mathrm{~m} \Omega$ were carried out and the results of Joule heat were coupled to the thermal analysis model to obtain the steady-state temperature distribution.

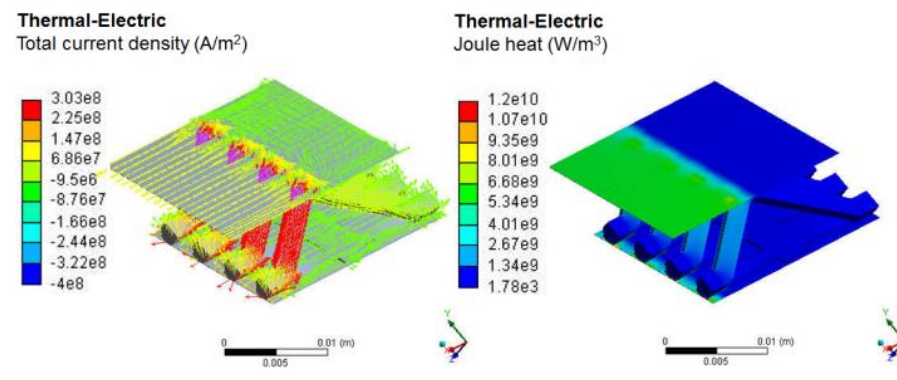

Fig. 6 Results of current density and Joule heat $(\mathrm{Rc}=1 \mathrm{~m} \Omega)$

\section{3) Results of temperature distribution}

The operation temperature of the RF contact is very important for its operation safety as it can deteriorate the mechanical strength of the base materials. Under higher temperature, materials can lose their elastic properties, and with contact force applied the structure inclines to be plastic deformed or creeped. The force relaxation could increase the contact resistance and a vicious circle generated. In addition, with the plastic deformation and creeping happens, gaps may be generated at the electrical contact areas which could induce severe arcing and destroy the RF contact rapidly. The 
temperature distribution, especially the maximum temperature on the RF contact is worth to be carefully researched and the engineering solutions to control the temperature are necessary to be investigated.

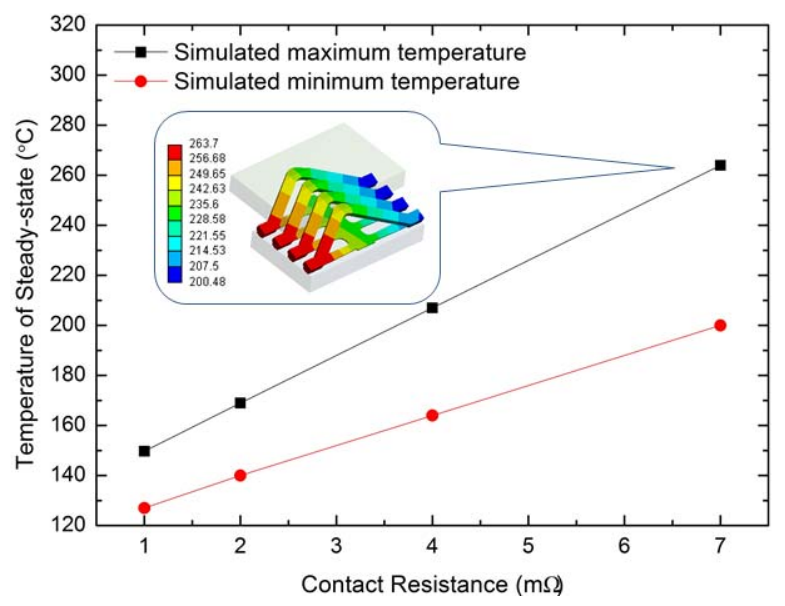

Fig. 7 Variation of $\max / \mathrm{min}$. temperature on the RF contact with the contact resistance $\left(\mathrm{HTC}=6300 \mathrm{~W} / \mathrm{m}^{2} \cdot{ }^{\circ} \mathrm{C}\right)$

For the active cooling of the conductors, its cooling performance is restricted by the flowing velocity or mass flow rate. $0.5 \mathrm{~m} / \mathrm{s}$ is a reasonable value for the real component cooling, and under such velocity the HTC is $6300 \mathrm{~W} / \mathrm{m}^{2} \cdot \mathrm{C}$. The relationship between the contact resistance and the max./min. temperature on the RF contact is shown in Fig.7. With the increasing of the contact resistance, the max./min. temperature is linearly increased accordingly. And under the contact resistance of $7 \mathrm{~m} \Omega$, the maximum temperature on the $\mathrm{RF}$ contact reaches to $264 \mathrm{C}$ which is higher than the $\mathrm{CuCrZr}$ 's temperature limit $(250 \mathrm{C})$ for steady state operation. The following solutions could be used to decrease the louver temperature: minimizing the contact resistance to decrease the heat deposition and improving the cooling efficiency of the cooling system.

Increasing the cooling water velocity can raise the HTC on the cooling surfaces accordingly. For the case that contact resistance of $7 \mathrm{~m} \Omega$, the study to find the efficiency by increasing the cooling water velocity to decrease the maximum temperature on the RF contact was carried out.

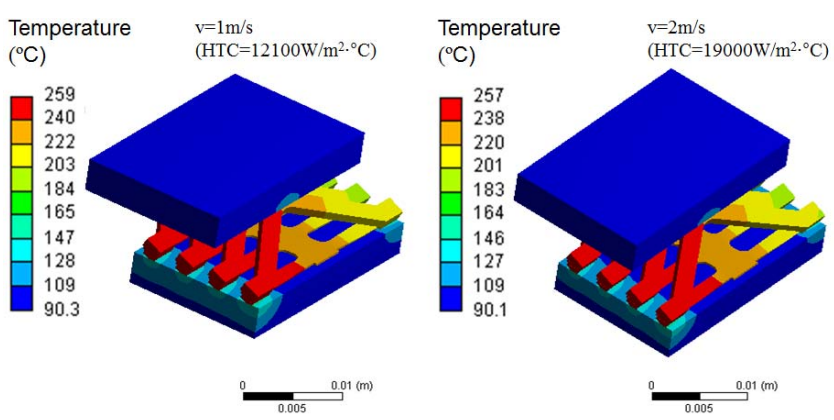

Fig. 8 Temperature distribution on the RF contact under the cooling water velocities of $1 \mathrm{~m} / \mathrm{s}$ and $2 \mathrm{~m} / \mathrm{s}$

As Fig. 8 shows, when the velocity of the cooling water increased to $1 \mathrm{~m} / \mathrm{s}$ and $2 \mathrm{~m} / \mathrm{s}$, the maximum temperature of the $\mathrm{RF}$ contact decreased only by $2 \mathrm{C}$. The low sensitivity of the louver maximum temperature to the cooling water velocity is due to the low thermal contact conductance at the contact areas and the low thermal conductivity of the base material (316L) of the RF conductors. It's worth mentioning that, increasing the cooling water velocity can induce a larger pressure drop in the cooling system and can lead to more serious erosion to the cooling channel surfaces. From the above analyses it seems that $0.5 \mathrm{~m} / \mathrm{s}$ is enough for the RF contact's cooling.

Based on the above analysis, minimizing the contact resistance is the key point to control the operation temperature on the RF contact. For the contact resistance controlling point of view, applying functional coating can improve the contact performance so as to decrease the contact resistance. For the $\mathrm{CuCrZr}$ louvers, Au-Ni coating which has higher wear resistivity could also be applied. For the $316 \mathrm{~L}$ made conductors, a thin layer of $\mathrm{Rh}$ will be electroplated on current flowing surface to decrease the contact resistance as well as to protect the conductors from wear.

\section{PERFORMANCE STUDY OF AU-Ni/RH COATINGS UNDER ITER RELEVANT OPERATION CONDITIONS}

Aiming to realize the safely operation of the RF sliding contacts under ITER relevant work conditions, the coating materials that applied should have good thermal standing without serious degradation of coating properties such as hardness, electrical resistivity and attachment force. Thermal ageing test and characterizations were performed towards the samples and the thermal ageing effects to the coatings' wear performance were investigated through tribological and electrical tests.

\section{A. Thermal ageing test}

\section{1) Materials and methods}

$\mathrm{CuCrZr}$ and $316 \mathrm{~L}$ plate samples with the dimensions of $10 \mathrm{~mm} \times 8 \mathrm{~mm} \times 2 \mathrm{~mm}$ were manufactured. $\mathrm{Au}-\mathrm{Ni}$ and $\mathrm{Rh}$ coatings were electroplated on them respectively. It is reported that significant grain coarsening of the pure gold under high temperature can be easily happened [17]. As ITER RF contact will be backed under $250{ }^{\circ} \mathrm{C}$ for outgassing, the thermal stability of the coating is a key factor which will influence the contact materials' lifetime. In order to investigate the thermal ageing effect to the samples' coating surface state as well as the diffusion between different material layers, all these samples were baked under ITER relevant baking conditions (vacuum: $10^{-6} \mathrm{~Pa}$, temperature: $250 \mathrm{C}$, baking duration:500h).

The crystal structure information includes crystal phase, crystallite size, and lattice constants of different coatings was characterized by using an X-ray diffractometer (XRD, BRUKER D4 ENDEAVOR, Germany) with Ni filter $\mathrm{Cu} \mathrm{K}_{\mathrm{a}}$ radiation $(\lambda=1.54184 \AA, 40 \mathrm{kV}, 40 \mathrm{~mA})$. The $\mathrm{X}$-ray diffraction data was collected from $10^{\circ}$ to $100^{\circ}$ in $2 \theta$ with a $0.0157^{\circ}$ step scan. And the morphology of the samples as well as diffusion phenomena was observed by a JSM-6510LV SEM with EDS.

\section{2) SEM and EDS results}

Gold and copper are two materials that can easily diffuse into each other even at room temperature. For $3 \mu \mathrm{m}$ gold coating, within one month under $300^{\circ} \mathrm{C}$ using temperature, the copper oxides can be observed on the top of the gold film[18]. It has been shown that when thin electroplated gold on copper substrates is exposed to temperatures below $250^{\circ} \mathrm{C}$, mass diffusion of copper can occur resulting in a substantial degradation of an electrical connection[19]. Ni is commonly used on electrical contact industry as diffusion barrier between Au coating and copper substrate. 

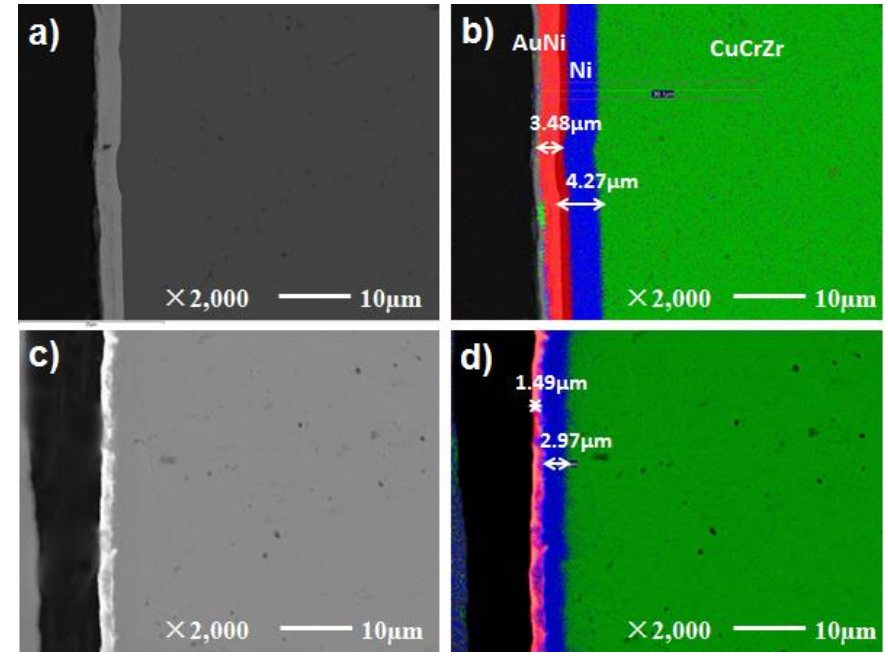

Fig. 9 SEM image and EDS mapping of the Au-Ni coating on $\mathrm{CuCrZr}$ : a) Cross-section SEM image of the original sample; b). Cross-section EDS mapping of the original sample; c). Cross-section SEM image of the therma aged sample; b). Cross-section EDS mapping of the original thermal aged sample

For ITER RF contacts, the coating should have good stability under long period of high temperature baking, so a relative thick Ni layer (about $4.3 \mu \mathrm{m}$ ) was applied. On the $\mathrm{Ni}$ layer, a $3.5 \mu \mathrm{m}$ thick $\mathrm{Au}-\mathrm{Ni}$ layer was plated. By performing EDS point analysis in the Au-Ni layer, before thermal ageing, the compositions are: $\mathrm{Ni}-2.09$ wt.\%, $\mathrm{Cu}-1.59$ wt.\%, $\mathrm{Au}-96.32$ wt.\%. Before thermal ageing the interfaces of materials were clear (Fig. 9). However, after thermal ageing, coatings' thickness has been changed, and decreasing of $\mathrm{Au}-\mathrm{Ni}$ and $\mathrm{Ni}$ layers has been observed. Moreover, the serious diffusion of $\mathrm{Ni}$ into Au-Ni was clearly observed. Under high temperature the solid solution of $\mathrm{Ni}$ into $\mathrm{Au}$ increased, and saturated $\mathrm{Ni}$ precipitated from the Au-Ni solid solution. The precipitated Ni phase accelerated the diffusion of $\mathrm{Ni}$ into $\mathrm{Au}-\mathrm{Ni}$ and at last, the serious invasion of $\mathrm{Ni}$ into Au-Ni layer occurred. After thermal ageing, the compositions of Au-Ni coating are: Ni-3.24 wt.\%, $\mathrm{Cu}-1.59$ wt.\%, Au-95.17 wt.\%. The increasing of Ni into the $\mathrm{Au}-\mathrm{Ni}$ layer can increase both the hardness of the Au-Ni layer and the electrical resistivity. And the increase of electrical resistivity could induce larger RF losses as RF current prone to flow in the skin surface of the louvers due to skin effect. Based on the above experience, the thickness of $\mathrm{Ni}$ and $\mathrm{Au}-\mathrm{Ni}$ should be increased to minimize the diffusion effects.

As Fig.10 shows, an interlayer of $\mathrm{Ni}$ was plated on the $316 \mathrm{~L}$ surface and then a gold flash was applied between the $\mathrm{Ni}$ and $\mathrm{Rh}$ layer. The function of gold flash is to protect the $\mathrm{Rh}$ plating bath from pollution caused by the substrate materials. After electroplating, cracks were observed and the average crack width is about $100 \mathrm{~nm}$. After thermal ageing test, the main change of the $\mathrm{Rh}$ coating was the enlarging of crack spacing and the quantity of the cracks was also increased. However, no obvious diffusion happened between the different coating layers and coating to the $316 \mathrm{~L}$ substrate. What's more, the cracks growth had no distinct effects to the attachment performance of Rh coating, and no peeling phenomenon has been observed.
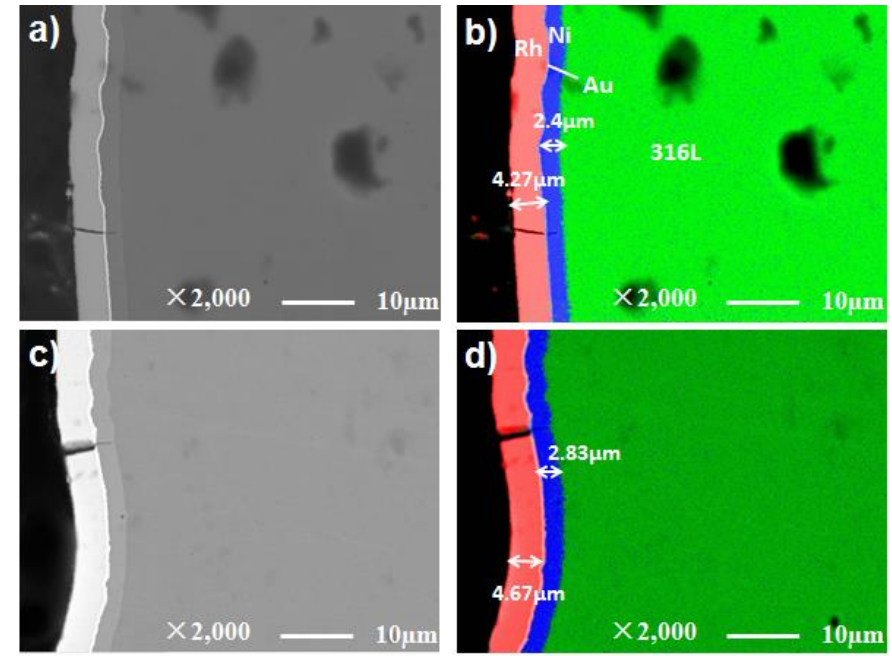

Fig. 10 SEM image and EDS mapping of the Rh coating on 316L: a). Crosssection SEM image of the original sample; b). Cross-section EDS mapping of the original sample; c). Cross-section SEM image of the thermal aged sample; b). Cross-section EDS mapping of the original thermal aged sample

\section{3) XRD results}

Crystallite sizes of the coatings are closely related with the coatings' mechanical properties like hardness which would affect their wear performance. This information can be studied from the XRD patterns by observing the peak's full-width at half-maximum (FWHM) [20].

As shown in Fig.11, before thermal ageing, the peaks of $\mathrm{Au}$ $\mathrm{Cu}$ and $\mathrm{Ni}$ phase were found from the XRD pattern. The Ni peaks comes from the interlayer of the Au-Ni coating and the $\mathrm{Cu}$ peaks are from the substrate. From peak (111) and by using Scherrer formula, the crystallite size is about $21 \mathrm{~nm}$. After thermal ageing, the preferred orientation of the $\mathrm{Ni}$ and $\mathrm{Cu}$ phases changed from (111) to (200). The Au (111) peak shifted about 0.03 degree to the low $\theta$ direction which was caused by the diffusion of copper atoms (with larger atom radius than $\mathrm{Ni}$ ) into the $\mathrm{Au}$ layer. Compared with the initial samples pattern, after thermal ageing, the FWHM of the Au peaks didn't decrease obviously which means that the Au-Ni coating has good thermal resistance without serious grain coarsening. By using peak (111), the calculated crystallite size is about 25.5 $\mathrm{nm}$.

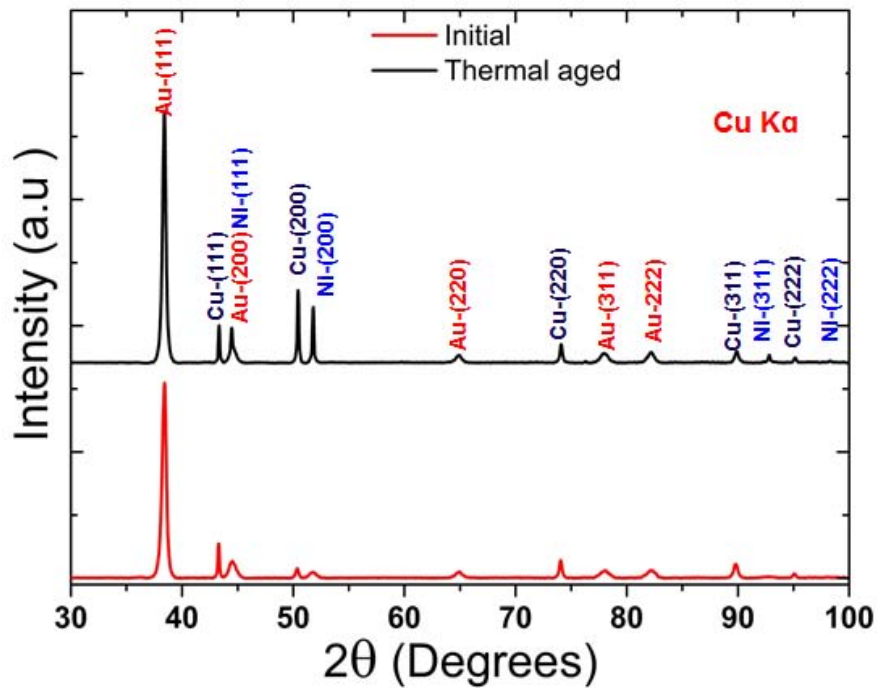


Fig. $11 \mathrm{XRD}$ patterns of Au-Ni coating on $\mathrm{CuCrZr}$ before and after thermal ageing test

The crystallite size of the Rh coating before thermal aging is about $7 \mathrm{~nm}$, with lattice constant of $0.3795 \mathrm{~nm}$. In Fig. 12, austenite peaks were found in the pattern due to the cracks on the Rh coating surface as well as the X-ray penetration. For the same reason, small amount of $\mathrm{Au}$ has been found as it acts as the interlayer between $\mathrm{Rh}$ and $316 \mathrm{~L}$. The crystallite size grows to $15 \mathrm{~nm}$ during thermal aging with lattice constant about $0.3795 \mathrm{~nm}$. The peak intensity increased after thermal ageing is due to the reduction of the microstructural defects and the consequent improvement of the film crystallinity [21].

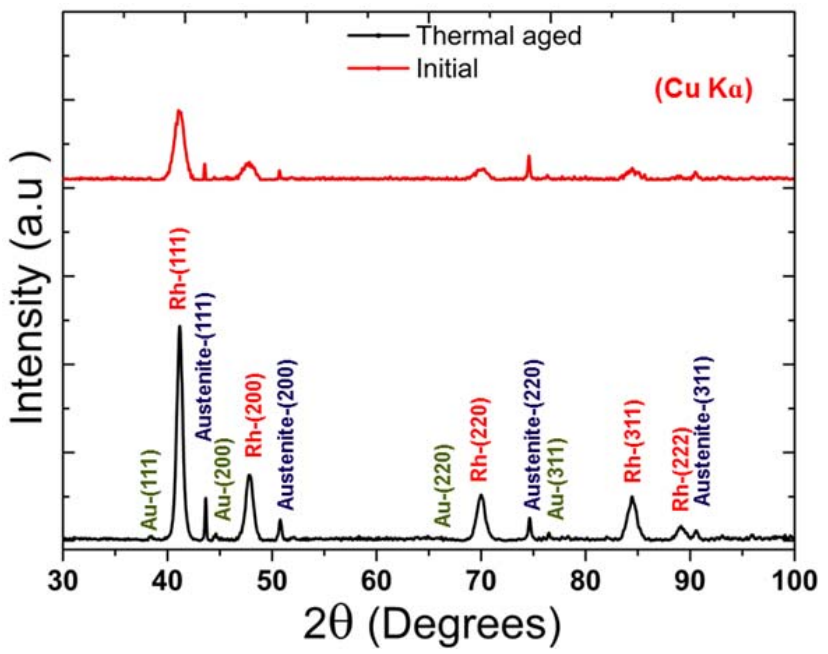

Fig. 12 XRD patterns of $\mathrm{Rh}$ coating on $316 \mathrm{~L}$ before and after thermal ageing test

Based on the XRD analyses, both the Au-Ni coating on $\mathrm{CuCrZr}$ and $\mathrm{Rh}$ coating on $316 \mathrm{~L}$ had good thermal stability without serious grain coarsening. This good performance will benefit for keeping their wear resistivity after high temperature baking as well as during normal operation under high temperature.

\section{B. Electrical and tribological tests}

During the antenna operation, repetitive sliding will occur and wear is inevitable. Beside the abrasion loss, the coefficient of friction $(\mathrm{CoF})$ is also an interesting parameter that is expected to be measured, which can impact the design of the remote handling and motor drive systems. In order to investigate the wear and friction phenomena of the RF contact under ITER relevant conditions, a dedicated tribometer named Heatable Vacuum Material Triboligical \& Electrical Study Testbed (HV-MTEST) was developed in CEA.

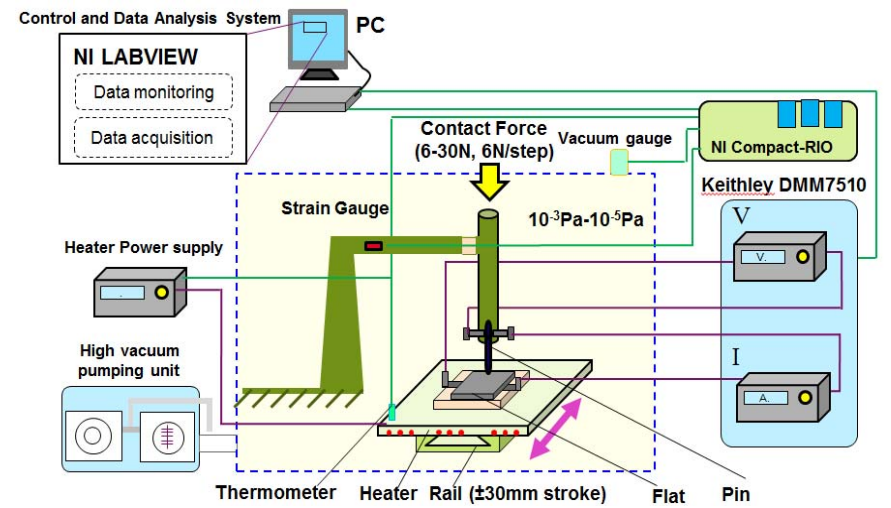

Fig. 13 Schematic of the HV-MTEST facility

As shown in Fig.13, in order to mimic the sliding of the RF contacts against their opposite conductors, a pin-on-plate sample configuration with reciprocating linear movement was used on HV-MTEST. The pin sample mimics the tip of the louver and the plate mimics the facing conductor. The tribometer is equipped with heaters and high vacuum pumping set. The samples can be tested steadily under high temperature up to $250 \mathrm{C}$ and to vacuum pressure below $10^{-5} \mathrm{~Pa}$. The normal contact force can be adjusted from $6 \mathrm{~N}$ to $30 \mathrm{~N}$. The electrical and tribological performance and the original and thermal aged samples were studied and compared on HV-MTEST.

\section{1) Materials and methods}

Plates used in the HV-MTEST tribometer were made of $316 \mathrm{~L}$ with the dimensions of $40 \mathrm{~mm} \times 30 \mathrm{~mm} \times 2 \mathrm{~mm}$. The same $\mathrm{Rh}$ electroplating process as the small plates was applied and a $\mathrm{Sa}=1.95 \mu \mathrm{m} \mathrm{Rh}$ coating was obtained. The thickness of the $\mathrm{Rh}$ coating is $(4.18 \pm 0.33) \mu \mathrm{m}$. The $\mathrm{CuCrZr}$ pin is a cylinder with length of $25 \mathrm{~mm}$ and diameter of $5 \mathrm{~mm}$. On the tip of the pin, a spherical surface with a radius of $8 \mathrm{~mm}$ was designed to act as the contact surface against the plate sample. The same electroplating procedure as the $\mathrm{Au}-\mathrm{Ni}$ on small $\mathrm{CuCrZr}$ plates was used. And the only difference is that, on the pin, the thickness of the Au-Ni was plated thicker which reaches to $(14.22 \pm 1.20) \mu \mathrm{m}$. The surface roughness of the Au-Ni on the pin is $2.14 \mu \mathrm{m}(\mathrm{Sa})$.

Sliding tests were performed on original samples and thermal aged samples under the same test parameters: normal contact force of $18 \mathrm{~N}$, sliding speed of $1 \mathrm{~mm} / \mathrm{s}$, vacuum $10^{-4} \mathrm{~Pa}$ and temperature of $200 \mathrm{C}$. For each sample, 2000 cycles of reciprocating sliding (16 $\mathrm{mm}$ stroke) were performed under the above test conditions which mimicked the ITER RF contacts' expected environment.

\section{2) Test results}

$\mathrm{CoF}$ and $\mathrm{R}_{\mathrm{c}}$ were recorded during the sliding cycles. By analyzing the sudden changes of the signals, the lifetime of the coatings can be obtained and the electrical contact performance can be evaluated.

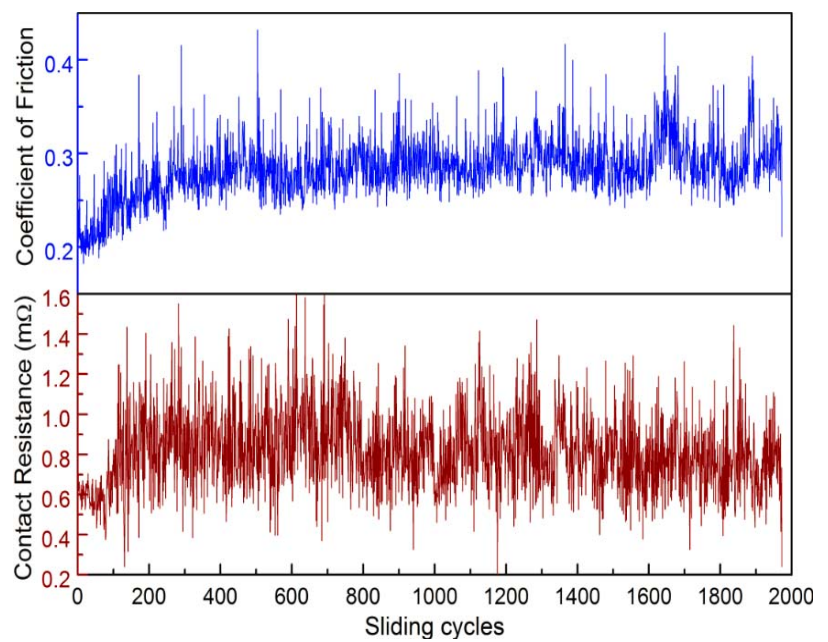

Fig. 14 Evolution of $\mathrm{CoF}$ and $\mathrm{R}_{\mathrm{c}}$ during 2000 cycles sliding tests (original samples) 


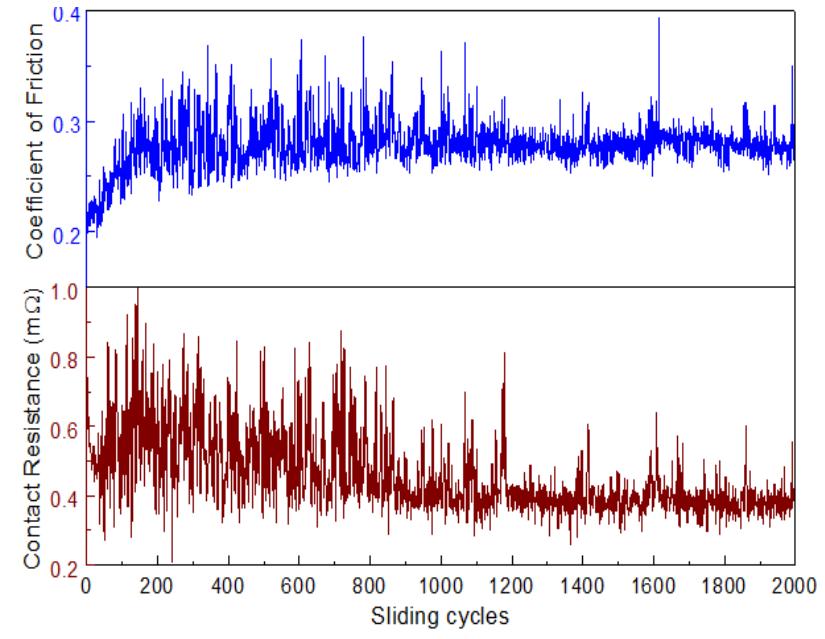

Fig. 15 Evolution of $\mathrm{CoF}$ and $\mathrm{R}_{\mathrm{c}}$ during 2000 cycles sliding tests (thermal aged samples)

As Fig.14 and Fig.15 show, $\mathrm{CoF}$ and $\mathrm{R}_{\mathrm{c}}$ of the original and thermal aged samples were similar for the first 50 cycles. For the original samples, during the first 100 cycles, the values of $\mathrm{CoF}$ and $\mathrm{R}_{\mathrm{c}}$ were relative stable without obvious change. This means that during the first 100 cycles, the wear of the Au-Ni was not serious or the wear was only occurred in the Au-Ni layer. After around 100 cycles, the $\mathrm{R}_{\mathrm{c}}$ increased suddenly. The sudden change of $R_{c}$ was caused by the Au-Ni layer's serious wear and removal. Between 100 to 500 cycles, the CoF increased gradually from about 0.2 to 0.32 . During all the 2000 cycles sliding test, the signals of $\mathrm{R}_{\mathrm{c}}$ and $\mathrm{CoF}$ were quite noisy.

Unlike the original samples, for the thermal aged samples, $\mathrm{R}_{\mathrm{c}}$ gradually increased from $0.4 \mathrm{~m} \Omega$ to $0.7 \mathrm{~m} \Omega$ and $C o F$ increased from 0.2 to 0.28 during the first 150 cycles. This phenomenon may be caused by the hardness change of the Au$\mathrm{Ni}$ coating after baking and also the coating interfaces/thicknesses changing as described in the last section. From cycle 1200 to cycle 2000 , the signals of $R_{c}$ and CoF are quite smooth, which indicates that during that time the wear of samples was mild. At the end, the $\mathrm{R}_{\mathrm{c}}$ of the thermal aged samples was only half than that of the original samples.
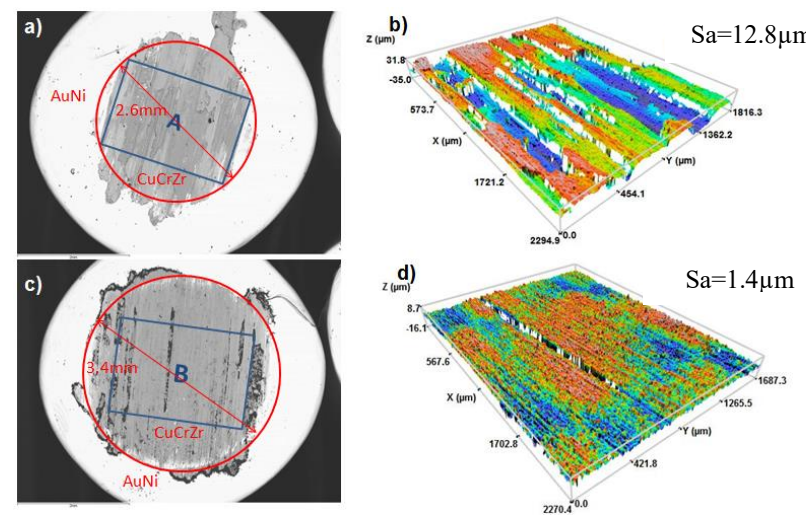

Fig. 16 SEM and confocal topography of the worn pins: a). SEM image of the original pin; b). Confocal image of zone A; c). SEM image of the thermal aged pin; b). Confocal image of zone B.

The surface state of the worn pin samples is shown in Fig.16. Serious abrasion wear occurred on the two pins. However, the abrasion loss of the thermal aged sample is much higher than the original sample. Based on the 3D profile image of the worn surface, the roughness of the original pin sample $\left(\mathrm{S}_{\mathrm{a}}=12.8 \mu \mathrm{m}\right)$ is much higher than the thermal aged pin sample
$\left(\mathrm{S}_{\mathrm{a}}=1.4 \mu \mathrm{m}\right)$. This can explain why the $\mathrm{R}_{\mathrm{c}}$ between the thermal aged sample is smaller than that between the original samples.

The wear on the plate samples are also of interest as it mimics a fixed ITER conductor. The possibility of replacing the worn conductor is low and costly. For this reason, applying a $\mathrm{Rh}$ coating which has very high hardness to protect the $316 \mathrm{~L}$ conductor from wear is necessary. In Fig.17, the surface state of the plate samples before and after sliding tests was checked under SEM. After sliding test, small areas of Rh peeling from the $316 \mathrm{~L}$ substrates and the $\mathrm{CuCrZr}$ cladding on the $\mathrm{Rh}$ surfaces were observed both on the original sample and thermal aged sample. Due to the high wear resistance of the original pin sample, the abrasion wear on the original plate is more serious than on the thermal aged plate sample (with larger areas of Rh peeling). However, due to the small size of the $\mathrm{Rh}$ peeling areas, during sliding, there was no direct contact between the pin tip and the $316 \mathrm{~L}$ substrates. In other words, the $\mathrm{Rh}$ coatings had the functions like wear protection and electrical contact resistance reduction during the whole sliding cycles. The good attachment performance of $\mathrm{Rh}$ on the $316 \mathrm{~L}$ substrate was thus validated.

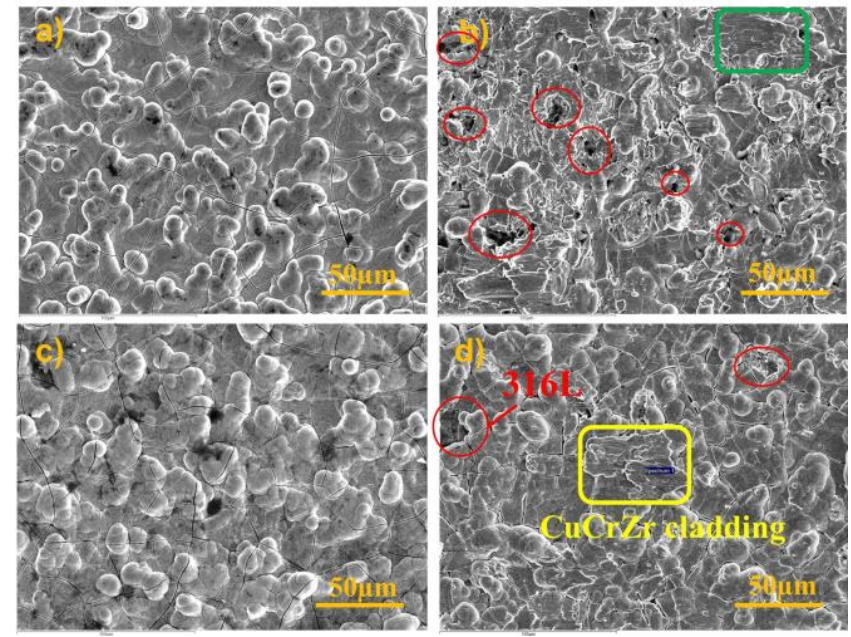

Fig. 17 SEM images of the Rh on 316L plates: a). Original sample before sliding test; b). Original sample after sliding test; c). Thermal aged sample before sliding test; d). Thermal aged sample after sliding test.

\section{CONCLUSION}

Through the failure analysis of the previous tested RF contact prototypes, burning and melting were found to be their main failure phenomena. The RF losses due to contact resistance and material bulk resistivity are the main heat sources that caused the above failures. $316 \mathrm{~L}$ and $\mathrm{CuCrZr}$ were evaluated in this paper as possible base materials for manufacturing the conductors and contact louvers. Although active cooling is essential for the RF contact's thermal removal, based on the electrical-thermal analyses, the temperature on the contact louvers is little sensitive to the cooling performance but sensitive to the contact resistances. The application of $\mathrm{Rh}$ and Au-Ni coatings on $316 \mathrm{~L}$ and $\mathrm{CuCrZr}$ surfaces respectively was assessed through thermal aging and tribological tests. The decrease of the Au-Ni and Ni layer thicknesses due to diffusion was observed after $500 \mathrm{~h}, 250^{\circ} \mathrm{C}$ baking without interface defects generation. According to the ITER expected baking durations, the coating thickness of $\mathrm{Au}-\mathrm{Ni}$ and $\mathrm{Ni}$ should be reassessed. For Rh coating, although cracking increased after baking, no obvious effect of cracking to its wear resistance has been observed. Due to the Au-Ni material and its coating interface modification during baking, the thermal aged 
Au-Ni coating is prone to be worn out compared with the original coating. In order to reduce the wear on the RF contact louvers, lower contact force can be used, but its effect to the contact resistance should be investigated. The replacing of the conductors' base material to $\mathrm{CuCrZr}$ is an interesting future work as $\mathrm{CuCrZr}$ has much higher thermal conductivity compared with $316 \mathrm{~L}$. However, the Rh coating performances on $\mathrm{CuCrZr}$ should be investigated.

\section{ACKNOWLEDGMENT}

This work was set up with a funding support of ITER Organization (SSA-50 CONV-AIF-2015-4-8). The authors would like to show thanks to Radiall ${ }^{\circledR}$ and Multi-Contact ${ }^{\circledR}$ for their help towards the samples manufacturing. The views and opinions expressed herein do not necessarily reflect those of the ITER Organization.

\section{REFERENCES}

[1] R. Budny, Comparisons of predicted plasma performance in ITER Hmode plasmas with various mixes of external heating. Nuclear Fusion, 2009. 49(8): p. 085008.

[2] M. Shimada, Overview of goals and performance of ITER and strategy for plasma-wall interaction investigation. Journal of nuclear materials, 2005. 337: p. 808-815.

[3] D. Swain and R. Goulding, ITER ion cyclotron system: Overview and plans. Fusion Engineering and Design, 2007. 82(5): p. 603-609.

[4] A. Borthwick, Mechanical design features and challenges for the ITER ICRH antenna. Fusion Engineering and Design, 2009. 84(2-6): p. 493-496

[5] F. Ferlay, First analysis of remote handling maintenance procedure in the hot cell for the ITER ICH\&CD antenna-RVTL replacement. Fusion Engineering and Design, 2013. 88(9): p. 1924-1928.

[6] P. Lamalle, Status of the ITER Ion Cyclotron H\&amp;CD system. Fusion Engineering and Design, 2013. 88(6-8): p. 517-520.

[7] C. Day and D. Murdoch, The ITER vacuum systems. in Journal of Physics: Conference Series. 2008. IOP Publishing.

[8] A. Argouarch, Steady state RF facility for testing ITER ICRH RF contact component. Fusion Engineering and Design, 2013. 88(6): p. 1002-1006.

[9] J. Hillairet, R\&D activities on RF contacts for the ITER ion cyclotron resonance heating launcher. Fusion Engineering and Design, 2015. 96: p. 477-481.

[10] A. Argouarch, RF contact development for the ITER ICRH antenna. in AIP Conference Proceedings. 2014.

[11] J. Bernard, New high power CW test facilities for ITER ICRH components testing. Fusion Engineering and Design, 2011. 86(6): p. 876-879.

[12] S. Wikman, Assessment of materials data for blanket materials within the European contribution to ITER. Journal of Nuclear Materials, 2013. 442(1): p. S414-S419.

[13] A. Chatterjee, Comparative study of approaches to assess damage in thermally fatigued $\mathrm{Cu} \mathrm{Cr} \mathrm{Zr}$ alloy. Journal of Nuclear Materials, 2016. 474: p. $120-125$.

[14] R. Niranjan, Surface modifications of fusion reactor relevant materials on exposure to fusion grade plasma in plasma focus device. Applied Surface Science, 2015. 355: p. 989-998.

[15] C. Obitz, Erosion corrosion of $\mathrm{CuCrZr}$ specimens exposed for simulated ITER operational conditions. Nuclear Materials and Energy, 2016.

[16] L. Morgan, J. Shimwell and M. Gilbert, Isotopically enriched structural materials in nuclear devices. Fusion Engineering and Design, 2015. 90: p. 79-87.

[17] M. Rost, D. Quist and J. Frenken, Grains, growth, and grooving. Physical review letters, 2003. 91(2): p. 026101.
[18] M. Schlesinger and M. Paunovic, Modern electroplating. Vol. 55 2011: John Wiley \& Sons.

[19] M. Pinnel and J. Bennett, Mass diffusion in polycrystalline copper/electroplated gold planar couples. Metallurgical Transactions, 1972. 3(7): p. 1989-1997.

[20] L. Marot, Characterization of magnetron sputtered rhodium films for reflective coatings. Surface and Coatings Technology, 2008. 202(13): p. 2837-2843.

[21] A. Belahmar and A. Chouiyakh, Sputtering Synthesis and Thermal Annealing Effect on Gold Nanoparticles in Al 2 O 3 Matrix. Journal of Nanoscience and Technology, 2016: p. 100-103. 